\title{
Power, corruption and lies: mis-selling, misconduct and the production of culture in financial services
}

Matthew J Brannan

\begin{abstract}
The extent of recent misconduct in retail financial services questions assumptions that misselling is perpetrated by rogue traders dealing in sub-prime markets. Yet we know little about the organizational dimensions of mis-selling and specifically how new employees are introduced to and subsequently enact mis-selling behaviour when not explicitly encouraged to do so. This article seeks to understand the mechanics of mis-selling through an ethnographic account of the opening of a new retail financial services call centre, and analysis of the ritual nature of the sales interaction. The study documents the mechanics of mis-selling; training, induction and initial work of direct sales agents to better understand the complexity, social relations and organization of mis-selling, together with the way in which regulation and management regimes shape sales practice and consequent employee behaviour. The critical analysis of sales rituals allows us to explain how mis-selling becomes embedded in organizational practice and contributes to our understanding of the everydayness of mis-selling in contrast to approaches that focus either on individual decisionmaking or on cultural explanations.
\end{abstract}

\section{Keywords}

Culture, Ethnography,,Misconduct, Mis-selling, Regulation, Retail Financial Services, Risk 
Despite well-established schemes for redress, headline-grabbing fines for transgressive firms and a growing industry of claims specialists, little is known about the organizational dimensions of mis-selling. Specifically we are yet to understand how new employees are introduced to and subsequently enact mis-selling and the scope employees have in performing or resisting mis-selling. These are particularly important questions in cases where organizations formally reject mis-selling and/or offer regulation to prevent it. Defined here as the deliberate, reckless or negligent sale of products and services, mis-selling is performed in organizational settings within the context of regulated markets with statutory bodies ${ }^{1}$ and legal protections for customers (Benston, 1999) that in theory should prevent or at least challenge mis-selling. The inability of firms and regulators to prevent mis-selling is claimed by some to be the 'stand-out systemic problem in the UK retail financial market' (Ferran, 2012: 249). Formal regulation focuses on the notion of 'treating customers fairly' (TCF) and requires 'senior management to work out for themselves what practices guarantee fair treatment ... and is premised on the idea of (enforced) "self-regulation”' (Georgosouli, 2011: 406). This implicitly assumes that individual firms have the capacity (and interest) to regulate their employees to exercise self-control in the sales process. Yet empirical studies note that regulation of conduct is broadly treated as an 'add on' rather than a centrally located management activity. Moreover, responses to regulatory regimes are more emotional and less calculative than is frequently assumed, and compliance is often delegated, shifting responsibility to managers to determine the 'interpretation, implementation and evaluation of what complying with TCF entails for their business units’ (Gilad, 2011: 325).

The regulatory framework thus makes a number of assumptions that seem ill suited to the market for financial services whilst drawing heavily upon inappropriate presumptions about the embedding of regulation within organizational contexts. Given that mis-selling is far from 
'an aberration, a one-off, [or] unrepeatable episode' (Black and Nobles, 1998: 789) and that enhanced regulation is unlikely to be effective, an empirical focus on front-line employees and their direct managers in understanding mis-selling is thus essential.

Persistent and systemic mis-selling has significant implications. Formal schemes of redress have imposed fines on firms, which also face indirect market sanctions and loss of both credibility and business (Karpoff et al., 2008). In the UK, for example, fines for mis-selling include over $£ 10$ billion for pensions, £2.6 billion for endowment mortgages and over $£ 16$ billion for payment protection insurance (PPI). Moreover, of the 13 million PPI complaints since 2007, 70 per cent have been upheld (FCA, 2014), with many well-known financial institutions implicated. Questionable practices in corporate finance such as foreign exchange and interest rate fixing, accusations of drug-money laundering and allegations of toxic cultures (Alloway et al., 2012) have further fuelled public anxiety and political concerns in relation to mis-selling of pensions (Watson, 2008), PPI (Ferran, 2012) and mortgage products (Ashton and Hudson, 2012).

The sale of financial products and services takes place within a context of both changing markets and consumer culture. Some critical commentators, for example, urge us to see the link between the global financial crisis (GFC) and culture more generally, or the 'cultural conditions of possibility' (Allon, 2009: 370, emphasis original) that produce everyday financialized identities. In this sense, the purchasing of financial products, the increasing complexity and growth of these products, and the consumption that they facilitate are essential markers of status and a 'prism through which a range of social values are expressed' (Nayak and Beckett, 2008: 409). This trend has intensified over the last 30 years in addition to individuals being increasingly encouraged to take responsibility for their own financial 
planning and decision-making, with greater onus placed on the personal provision for a range of financial services. It is likely therefore that we are all increasingly exposed to mis-selling as a consequence of either the direct transfer of responsibility or a 'nudge' (Thaler and Sunstein, 2009) in a free market direction. Those without financial cultural capital (Cooper, 2008) are especially at risk.

Although mis-selling is yet to be fully explored within MOS, understanding the organizational dimensions of mis-selling could potentially draw upon an extensive literature pertaining to unethical conduct at work. In order to be persuasive, however, any attempt to understand systematic mis-selling must provide an explanation of the collective extent of mis-selling behaviour given that individual agents always have the ability to choose more ethical approaches to sales. Secondly, given that regulatory regimes are in place, and the importance of compliance is generally well understood (MacNeil, 1999), explanations must resolve the practical and theoretical puzzle that makes sense of mis-selling despite apparent enforcement and evident consequences for malpractice.

In order to shed light on these issues, this article provides an analysis of the opening of a new retail financial services call centre. By exploring the training, induction and initial work of sales agents, I draw attention to the way in which regulatory and managerial regimes shape employee thinking and behaviour as well as the terms of engagement with which interaction with customers takes place. I then present an analysis of sales interactions - the central defining characteristic of all sales work - as ritualized practice. The anthropological notion of ritual, defined here as 'the performance of more or less invariant sequences of formal acts and utterances not encoded by the performers' (Rappaport, 1992: 249), is invoked in 
acknowledgement of the symbolic, material and embodied nature of repetitive sales interactions as revealed through participant observation.

Beyond defining mis-selling as worthy of investigation, and providing a case study of misselling in action, this article's contribution lies in explaining why individuals engage in misselling when not explicitly instructed to do so and demonstrates the centrality that ritual plays in this. Detailed and careful analysis is shown to offer the potential to comprehend how performance of ritual 'express(es) cultural values; it "says” something and therefore has meaning as part of a ... system of communication’ (La Fontaine, 1972: Xvii), and one which predisposes agents to mis-selling. Critically, however, I draw attention to the relation between ritual and culture, and argue that through the learning and performing of ritual practice, sales agents actually produce culture. The present study thus provides an exploration of the processes by which mis-selling becomes accepted organizational practice, and contributes to our understanding of the 'everydayness' of mis-selling whilst making a wider point about the value of understanding the production of culture in contemporary organizations, and the methods that we might use to achieve this.

The article is organized as follows. Firstly, I set out mis-selling as a complex social problem. In doing this I draw insights from a range of perspectives that make sense of mis-selling as either an individual or a collective problem. I then delineate the organizational context in which the research was conducted, together with the research methodology that was used to investigate the problem, and provide details of analytical processes pursued. I then present my ethnography and analysis. 


\section{Literature review}

A systematic literature review reveals mis-selling to be a topic that has received scant scholarly attention. The MOS literature, however, offers a number of potentially important theoretical resources that have been used to understand unethical conduct in a wider context. In very broad terms, our knowledge and understanding of unethical behaviour at work is built upon a long-established literature relating to employee conduct (Kaptein, 2011; see KishGephart et al., 2010 for a meta-analysis) and ethical decision-making (Gunz and Gunz, 2007; Watson, 2003). Research that aims to better understand unethical behaviour at work (of which mis-selling is an obvious example) focuses largely on the psychological exploration of the antecedents of unethical choice (Treviño and Youngblood, 1990; Ashkanasy et al., 2006). This work is primarily informed by the view that unethical behaviour is an irrational departure from organizational norms and is thus an inherently individualistic form of analysis. Despite an atomistic focus, researchers in this tradition note the way in which unethical behaviour can spread beyond the individual. Yet rather than broaden out the analysis to a collective level, this approach instead reinforces the role of the unethical individual as a source of 'contagion' to the wider organizational community (Felps, 2006; Gino et al., 2009). The small number of high-profile criminal cases for financial misconduct (the prosecution of Tom Hayes ${ }^{2}$ for collusive fixing of bank lending rates, for example) act to reinforce the presumption that financial crime is generally perpetrated by 'rogue traders' acting alone and in contravention of organizational protocols.

Outside the MOS field, and when understood as a form of white-collar or corporate crime, mis-selling might usefully be interrogated from a criminological perspective. Work in this tradition repeats many of the assumptions outlined above by seeking explanatory factors that account for individual decisions to engage in unethical sales practice. These common 
assumptions render organizations as merely the location and context for unethical behaviour and thus as passive actors. Yet even from within this frame, critical questions about the potentially determining role of the organizational context emerge. Karstedt and Farrall, for example, note that organizations that focus on selling constitute what they term 'risk environments'. This they argue is crucially important in framing individual decision-making; thus within the bounded environment of the firm, 'risk and opportunity are seen as concepts devoid of morality' (2006: 972). The medium of exchange, thus runs the argument, makes unethical behaviour a legitimate choice in the eyes of many employees. Yet the processes through which workplaces are able to shed their social and moral obligations are left tantalizingly unexplored. A further insight from criminological research is the 'ambiguous' (Nelken, 2012) way in which these forms of unethical activity are generally perceived in society. McBarnet argues that instances of misconduct that involve either 'creative compliance' (2006: 1097) or 'gaming the system' (2006: 1099) are generally construed as 'not strictly illegal' and hence occupy a morally uncertain, or 'grey', location in the mind of the general public.

The approach adopted here is to identify mis-selling as an important social problem and a phenomenon that deserves critical scrutiny in its own right. It is socially significant because the level of financial malpractice, whilst high, is under-investigated. Ericson and Doyle (2006) suggest for example that deceptive sales techniques are 'rife' within the insurance industry. Moreover, the prevalence of such unethical sales practice is almost certainly not reflected in criminal or civil sanctions. Thus, when considering the fines and redress issued in cases of mis-selling, Braithwaite and Braithwaite remind us that the level of the criminal threshold means that legal sanction operates in only the most extreme of cases. Therefore, MOS has a specific role to play firstly in drawing attention to the scope of this specific form 
of unethical behaviour and secondly in understanding the active role organizations play in shaping mis-selling behaviour. Understanding the collective dynamics of mis-selling is clearly a prerequisite for the design of organizational interventions and reforms to challenge or remove such practices. It is important that organizations take on this challenge, as 'the most effective preventive techniques will be non-criminal and early in a developmental sequence’ (2006: 1124).

\section{Making sense of malpractice in financial services: Cultural explanations}

The role that culture plays in financial firms features heavily in both academic and popular accounts of the industry and gained particular notoriety for its perceived role in the GFC (see inter alia Aldridge, 1997; Cohan, 2010; Johnson and Kwak, 2011; Kerfoot and Knights, 1993; Knights and Willmott, 1987; Knights and Willmott, 1992; Tett, 2009; Ward, 2010; Weeks, 2004). In accounting for malpractice in financial services, the cultural context is therefore an important aspect to explore, and may help explain why unethical practices are seen as being accepted, required and even promoted (Luyendijk, 2015) as part of life within the industry. Yet when invoked as an explanatory factor for misbehaviour, culture is often treated as an exogenous variable often portrayed as being externally imposed, be that from abroad, in the case of aggressive merger and acquisition (Buono at al., 1985), or cascaded downward from corporate elites. Both versions treat culture as a tool used in the sole pursuit of profitability, achieved by exponential growth of sales volume against fixed or falling capital levels.

In contrast, contemporary and historical accounts of employment relations within banking and financial services draw attention to widespread changes in the structure of the industry following deregulation. The way in which structural change produces cultural change is often 
implied rather than examined, but many have noted, for example, how financial institutions have moved from transactional to sales cultures (Chreim, 2006). In this context, Knights and McCabe (1997) show how a genuine interest in customers' welfare and satisfaction, which is often intangible and difficult to measure, is set aside in the face of more immediately pressing concerns, like cost minimization and target attainment.

The implications for employees of these changes are profound; Kerr and Robinson, for example, chart the transformation from 'professional advisors embedded in the community into sales people with sales targets to meet' (2012: 257). Such changes are often accompanied by the emergence of a workplace 'culture of fear' marked by regular rituals of humiliation (Kerr and Robinson, 2012: 258). Moreover, as cultures in financial services became progressively more short-term, aggressive and sales orientated, so the behaviour of individuals who, historically, 'in return for the promise of the career ... undertook to manage themselves in the most profound sense to ensure diligent performance and deep conformity with the organization’s culture' (Tempest et al., 2004: 1530) became more instrumental and less predictable.

The concept of culture therefore has potentially much to say in explaining the pressure to achieve targets in financial services and the impact this has on employee behaviour. However, as Dietz et al. remind us that, in complex organizations with many subunits (such as retail finance), the notion of a unified organization service climate may be largely mythical (2004: 87). Furthermore, Harris (2002) shows that the cultures of different banking organizations vary in quite important ways. Moreover, culture's power to determine the behaviour of its employees is likely to be limited by tensions inherent within it. Thus McCabe shows how espoused goals like customer service are inconsistent with the 
requirement to ‘regard everyone instrumentally as a potential sales opportunity’ (2009: 1561). In these tensions, it is argued, lie potential grounds for resistance, meaning that managerial objectives can and are contested by employees (Knights and McCabe, 1998: 173). We also know from work in this tradition that 'staff are not simply victims of management control, but are often active participants in the conditions that maintain and reproduce control and the stress and resistance that may follow as a result' (Knights and McCabe, 1998: 188). Thus cultural explanations, whilst possibly insightful, run the risk of providing over-deterministic and simplistic explanations that fail to account for variations and tensions in employee action.

By exploring how new recruits are introduced to the process of making sales, this article attempts to provide a more nuanced understanding of the enactment and embedding of misselling as well as employee resistance and accommodation. This approach aims to avoid providing a simple narrative of mis-selling that serves a particular predefined ideological objective. As Whittle and Mueller note, simple stories of the GFC often '(serve) to legitimate particular actions’ (2011: 131), but all too readily lead to superficial analysis and policy conclusions, without deeper reflection on the 'paradigmatic assumptions that ... contributed to the crisis in the first place' (Knights and McCabe, 2015: 199).

\section{Case study}

Praetorian (a pseudonym) is an international company engaged in what it calls the 'life assistance' business. Founded in the 1980s, it remains headquartered in the UK, but has operations in 15 geographical regions and at the time of the fieldwork (2008) was increasingly expanding its operations into developing economies. Throughout its initial decade of life, Praetorian made consistent losses, but achieved greater financial success 
through the development of markets for products that the company claimed 'help consumers cope with the anxieties and complexities of modern life' (company website, 2013). In 1998 the organization had over 7.6 million active policies, employed over 1000 people and was listed on the UK Stock Exchange.

Praetorian's business model is based on an implicitly commercialized conception of 'identity' and the explicit productization (Jaakkola, 2011) of 'protection'. Initially this included credit and debit cards following loss, theft or fraudulent use, and later it extended to the 'protection' of passports, keys and mobile phones. The company thus operates at the intersection of insurance and financial services. The firm's marketing focuses on foregrounding the 'risks' that an increasingly digital and busy life pose to its customers, and crucially to an abstract notion of customers' 'identity' which, the company claims, is increasingly 'at risk of threat and abuse' in addition to more conventional criminal risks, such as theft. Operating a 'business-to-business-to-consumer' (B2B2C) model, Praetorian contracts to offer its products to the customers of third-party organizations. Part of Praetorian's success is its ability to negotiate contracts with many well-known UK high-street banks and financial institutions. In some instances Praetorian’s products are bundled with the bank’s premium products, but, more generally, Praetorian secures the right to market its products to the bank's customers. Crucially, however, this marketing opportunity involves a number of deceptive practices that implicate both Praetorian and its commercial partners.

Upon issue of new payment cards, bank customers are instructed to call to 'activate' the card as a security mechanism to ensure that the card is safely received by the intended recipient. Customers are in fact calling Praetorian and thus providing it with an opportunity to market its products. In many cases, cards do not require activation and would have worked 
irrespective of the call to Praetorian. In a very real sense, then, at the core of Praetorian’s business model there is deceit and lack of transparency in terms of its specific relationship with its customers and the purpose of its interaction with them.

\section{Fieldwork}

The research on which this article is based has its origins in background research I was conducting to gain a more in-depth and nuanced understanding of work and employment in the service economy generally and call centres specifically. Praetorian was selected as a site for research because of its campaign to recruit new employees, which focused upon its 'unique, fun, friendly atmosphere'. At an open day to showcase the company and encourage applicants, representatives from the organization outlined its products and demonstrated the way in which they are sold. The manifest tension between the way in which the culture of the organization was promoted and the required working methods provoked a number of potential research questions.

I gained access to the organization setting as a new employee (sales adviser/agent) through an open recruitment process, and this allowed participation and observation of mis-selling in situ through employment. A covert approach to fieldwork was necessary because the practices that were common in the organization were not disclosed to customers and, as outlined above, involved embedded structural deceit. The research is ethnographic in the sense that it 'draws upon the writer's close observation of and involvement with people in a particular social setting and relates the words spoken and the practices observed or experienced to the overall cultural framework within which they occurred' (Watson, 2011: 205). Ethnography in its various forms has long been used as a way of exploring the everyday life of employees (Brannan et al., 2007) and is particularly appropriate for researching areas of employee 
behaviour which may be secretive or hidden because of their illicit nature (Bloor, 1997). In addition, and as a complement to the ethnographic approach, the research was informed by a reading of the 'Sociology of Everyday Life’ (Kalekin-Fishman, 2013), which aims to draw specific attention to practices that are often taken for granted or assumed. In practical terms this is achieved by placing the everyday experience of work at Praetorian, as most obviously manifest in the sales call, at the centre of my analysis. If ethnography provided a methodological approach, the sociology of everyday life provided a specific focus whilst acknowledging and accepting that the 'everyday always exceeds our ability to register it' (Highmore, 2002: 3).

Covert forms of social research are becoming increasingly rare as ‘ethics creep’ (Haggerty, 2004) - that is, the bureaucratic apparatuses that regulate social research - extends its scope and intensifies its efforts. There are a strong set of intellectual arguments that problematize covert research on the grounds of deception (Bulmer, 1982), trust (Homan, 1991) and the infringement of participants’ rights (Ali and Kelly, 2012), especially in relation to participants' ability to decide not to participate in the research. Yet objections to covert research are often based on what Spicker (2011) refers to as 'over-generalisations' that would apply to any research that embeds elements of deception. Although discussion of the role that deception plays in the research process is far from common, Fine (1993) reminds us that deception, whether intended or not, may actually be more common than is generally assumed. Specifically, he draws attention to a range of lies that may be told in pursuit of 'ethical' ethnography. These range from offering mock sympathy to participants and removing particular individuals and circumstances from academic accounts, to claiming precision in cases where the presentation of 'data' is more akin to the 'gist' of a situation. 
Gaining part-time employment within the case study organization for the purpose of research required and permitted both disclosure and concealment. The fieldwork, which started in May 2008, lasted for 12 weeks and amounted to over 400 hours of field observations. I joined as part of a recruitment drive when Praetorian opened a new office to cement growth and generate new sales. I maintained the deception that I was 'just' an employee to the team leader, other managers in the call centre and those customers that I interacted with. The organizational context of the research meant that observations took place within a semipublic (workplace) rather than a private setting. Whilst this does not offset the ethical problems of covert research, it does mean that the activities that were witnessed were not part of what Faden et al. refer to as a 'zone of protected activity' (1986), which is usually taken to mean private or intimate interactions. I conducted my employment duties to the best of my ability and in line with my employment contract, which, as a sales agent, involved the sale of identity-protection products priced at $£ 29.99, £ 79.90$ and $£ 129.99$ respectively.

As part of what might be framed 'situated ethics' (Calvey, 2008), I gave careful consideration to ethical issues surrounding the research. Employment was secured using my own name, qualifications and relevant work history (such as previous call centre experience). During the period of employment I disclosed the nature of the research to those that I worked with most closely, including members of the team to which I was assigned and many of those who were recruited with me. This gave the opportunity to discuss objections; however, none were voiced, whilst many co-workers were supportive and remained in contact with me following my withdrawal from the field. The account presented here refers to contextual, potentially identifying material only when necessary for the purpose of the argument and is provided six years after completion of the fieldwork. This protects those I worked alongside, as they are no longer employed by Praetorian. The narrative and analysis advanced in this article has 
been reviewed and 'fact checked' by a former employee who continued to work at the site for a number of years following my departure. In what follows I attempt to provide 'evocative stories that ring of truth' (Rosen, 2000: xi) and convey, in Sumantra Ghoshal's term, a 'sense of the smell of the place' (see Ghoshal, and Bartlett, 1994; Rynes, 2007, and De Vita, and Case, 2016). Quotes reported here were noted in situ, rather than recorded verbatim, and are indicative of the tenor of the discussion rather than explicit reproductions. I purposely employ as many voices as possible (as opposed to drawing, for example, from only my immediate teammates) in an effort to provide a sense of context from the call centre floor.

\section{Analytical process}

Observational notes were made in situ in a fieldwork notebook, and additional voice memos were recorded during the hour-long commute to and from the fieldwork site. I initially used my own personal experience, and specifically my emotional reactions to work, as a prompt for registering the characteristics of everyday life. I challenged myself to articulate those aspects of life that are so common as to lay hidden in plain sight. I noted the things that I found difficult and draining, the activities that were pleasurable and created a sense of enjoyment or fulfilment, as well as sources of frustration and anxiety. This provided a framework for observation and analysis of others (firstly immediate team members and then the wider workgroup) at work.

In designing an observational and analytical strategy, I pursued explicit dimensions of descriptive, structural and contrastive observations. Descriptive observations prioritized participants' descriptive accounts of their experience of Praetorian and their work histories in their own terms. Structural observations attempted to observe beyond surface appearance and to apprehend how participants made conceptual sense of their work - for example, the way in 
which different kinds of customers were categorized or the stages that new recruits went through to become trained agents. Moving beyond description to focus on 'types', 'sorts' and ‘categories’ provided an empirically grounded starting point for analysis. Finally, contrastive observations sought to explore the construction and maintenance of difference in the eyes of employees; differences between the canteen and the break room, or between the early and the late shift, are examples of differences I found to be considered important in the workplace. Cutting across these dimensions, I focused on what has been termed the 'anatomy of everyday life’ (Sztompka, 2008: 31) - that is, relations with others (customers, peers, trainers, managers) and repeated (rather than unique) events and happenings - whilst specifically noting the frequency and rhythms of those events. Finally, I looked to detect the development of ritualized, un-reflexive habitual behaviours and attendant biological cues for which my role as new recruit was especially apt.

The insights on which the claims made in this article rest are therefore multidimensional. In the first instance I draw on the sensuous experience of being in the field; working at Praetorian allowed me to experience, for example, the initial optimism with which many employees first start work, and to witness its gradual erosion and replacement by fear, boredom and isolation. This embodied register provided a sensitivity to observe the behaviour of others and a shared vocabulary with which to engage other employees as I sought to explore ways in which work processes and sales techniques became embedded. Did everyone feel the same way? Were all employees enacting similar behaviours? Talking about my behaviour, my feelings and myself provided an open and transparent platform to ask others about themselves, their behaviour and their work. 


\section{Notes from the 'Bear Pit'}

\section{'Buying in'}

Becoming part of the team at Praetorian began with a two-week induction programme focusing on company products and sales techniques. I joined a group of 20 other new recruits at the company's new call centre, which had been open for around a month. The preceding cohort of new staff, who had completed training, were just starting to take live calls. Induction and initial training were marshalled by Praetorian ‘old-timers’ (Blau, 1960) Jim and Cath, who both had extensive experience with Praetorian and claimed to have run the training workshop 'hundreds of times before'. This was reinforced with a reference to a 'sense of déjà vu’ and consolations of 'not to worry, we’ve seen this all before' and 'you'll get it in the end'. Training took the form of a number of workshops focusing upon the sales processes, reasons for failure (of a sale) and technical skills relating to use of the integrated computer and phone unit. Initial training was supplemented by a phased introduction to taking live calls and, as a form of legitimate peripheral participation (Lave and Wenger, 1991), provided opportunities for new recruits to put theoretical knowledge of sales into practice under close supervision from team managers and direct one-to-one call coaching. The structure of induction and training homologically mirrored the sales rituals that agents, through extensive repetition, came to internalize, draw upon and thus reproduce. Stressing the universality of the products and features that 'would benefit everyone', employees were invited to 'see the value' of products through the 'imagineering' of trainers who painted scenarios in which the products might be of use. The first sale Praetorian made therefore was to its employees, with the training processes casting new employees as potential customers for its products. 
The scope and extent of the sales training was both comprehensive and specific. Sales agents were taught the need to try to 'understand the importance of language'; an understanding and appreciation of subtlety would, it was noted, ‘make you better salespeople’. Agents practised two basic sales techniques: the 'feature route' and the 'scenario route'. Sales seminars outlined this clearly:

'Paint the scenario and shut up ... What would happen if you came home from work and found that someone had taken out a £7,000 loan in your name?’ A hushed silence fell over the seminar. For emphasis Cath pointed to a trainee: 'Well, what would YOU do? ... Remember, people buy from people they like, people who they identify with, and have similarities with ... make that connection.'

Making connections with customers was considered to be a key element of the sales ritual, and more specific techniques to achieve this included the matching of customer pitch and tone, listening for background cues in relation to lifestyle, and striking up a conversation about sporting events or happenings in the national headlines.

Post training, agents were phased into taking live calls and placed in teams, or 'pods', of between 6 and 10 sale agents under team leaders drafted from other Praetorian sites. The pod, the basic unit of work organization on the sales floor, was located within an open-plan office, laid out in a U-shaped configuration, with shoulder-high dividers between teams. Shift managers were located at one end of the call centre floor, and senior operational, technical, HR and sales managers were located upstairs.

New recruits were paid an annual salary of $£ 13,520$ (equivalent to $£ 6.50$ per hour, with 
minimum wage being $£ 5.73$ and UK median hourly earnings $£ 10.54)$. In addition to this, employees were promised bonus payments on achieving and exceeding targets. Sliding-scale bonus payments were triggered when employees met 90 per cent of their sales targets as aggregated over a month. Sales targets were broken down on a daily basis and amounted to employees selling policies to the value of $£ 500$ a day. Achieving their target would attain employees a 10 per cent bonus on their monthly salary, with an increasing bonus for greater sales levels.

\section{Producing the sales ritual}

Most recruits were eager and excited to make the transition to taking live calls, both to put into practice their new skills and for the chance to start earning bonuses, which many perceived as being routinely achievable. Initially new starters focused almost all their attention on gaining technical mastery over the telephone and computer system, which proved demanding even for those with previous call centre experience. Having been told to put their hands up for help, new employees could often be identified as persistently having their hands in the air whilst they worked. Drawing ridicule from more experienced (if only in terms of a matter of days) or more confident employees, many resisted such public displays of inexperience. Other bodily responses, such as attempts to cover the headset microphone when talking to a colleague whilst on a live customer call, seemed an almost impossible urge to resist and would only be removed with many hours of experience on the call centre floor.

Agents, initially at least, were given a script for each product that they sold alongside a 'route map for successful sales', with 'Different colour text [which] marks mandatory and advisory text'. Agents were taught that mandatory text related to words that must be spoken in order for a call to be 'compliant'. Employees understood that the firm was regulated by the FSA, 
which could ask at any time to visit the call centre or listen to a selection of calls, all of which were recorded. Praetorian also had its own compliance department, which selected calls randomly to determine compliance to sales guidelines. It was often quoted in training that 1 in 10 successful calls would be reviewed for compliance purposes. This gave the issue of compliance a real meaning for employees and was reinforced by incidences of sales agents being taken 'off-line' for training as a result of something identified in a 'compliance call'. In addition, agents would lose any monthly bonus if subsequent monitoring of calls found them to be non-compliant; this was known as 'compliance clawback' and was the issue most spoken about in relation to compliance.

The sale script, which formed the basis of the ritual sales interaction, offered a number of suggested open questions aimed at engaging the customer in conversation. The structure of the call led customers to believe that the sales agents were filling the time whilst their payment cards were being activated, a deception reinforced by the sales scripts, which made conversational suggestions such as 'I'm activating your card now. It will just take a few moments. Whilst you are on the line, can I talk to you about identity theft?' Customer objections were met with a pacifying statement in relation to the need to raise awareness.

Following engagement with customers, the sales agent then managed the call to a stage where key benefits of the product were outlined. Skilled agents learnt quickly which were the most attractive features of the product and would focus on these; less valued features could be left until the sale was close to being 'closed' and could be thrown in to sway the purchase. Agents were armed with a battery of statistics and figures to facilitate sales. Identity theft, for example, was carefully defined, in almost dictionary terms; this gave agents a sense of authority whilst on the call and invested the interaction with an almost benign tone. 
INSERT FIGURE 1 ABOUT HERE

\begin{abstract}
$=======$
Convincing customers to purchase - the sole objective of the sales ritual - was, however, a difficult and demanding task. Agents were taught a number of techniques for overcoming reluctant consumers as well as being provided with conversational cues or 'cures’ if further objections were raised. These amounted to an acknowledgement of the objection and then its deconstruction. Agents were coached to try to prevent a range of possible objections within the early stages of the call through careful construction and management of the interaction.
\end{abstract}

Unlike other call centres, tracking of team progress and success was expressed in terms of the generation of sales revenue rather than the volume of calls answered. On completion of a sale, agents were required to record their success with a marker pen on a mobile whiteboard, erasing the zero next to their name and replacing it with the value of the product sold. Successful sales also required the recalculation of the team's daily revenue figure and 'percentage to goal'. Through the ritual of publicly recording sales, sales agents knew exactly what they had secured for that day and how far away they were from their goal. Beyond this, for some employees, the documenting of sales also provided a sense of social affirmation and motivation:

'Standing up, taking your headset off, walking tall, putting your sale on the whiteboard - it makes me feel like the big man.' (Marc, sales agent)

The whiteboard also materialized a clear link between individual and team, targets and performance, and hence became a space for competition as well as collaboration: 
'I want to be competitive, I want to get on the board early. I like to be up and running.' (Paul, sales agent)

'I like the sense that I'm rewarded for my hard work and I can see how that helps the team out. Even though we don't have a team bonus, I still think it’s important to work as a team.' (Sam, sales agent)

The headsets that connected agents to the automatic call distribution system included a tether that allowed agents to get up and walk around the pod whilst remaining logged in to the system. It was not unusual to see agents updating the whiteboard in relation to a previous sale whilst talking to the next customer. Even when disconnected from the system, or not engaged on a call, agents tended to keep their headphones attached, often worn around the neck.

The tone from the top

An event early on in the fieldwork led to the sales floor being renamed the 'bear pit' and provides an insight into the tone that the company leadership tried to create within the call centre. Rumours had been circulating that a 'bigwig' was coming to meet the new recruits and inspect the new call centre. I noticed how the group of new recruits, after being called back from lunch early, seemed excited and chatted nervously, and there was a real buzz around the training room. Paul Pink from head office began:

'Shortly you'll be going live - you'll be in the bear pit! You'll be expected to be up to speed straight away. Remember your training, but also remember that we chose you! We've got confidence that you'll do well, but I don’t want you to do well - I want 
you to smash it!' He threw his hands up in the air, and members of the group responded with orchestrated cheering initiated by team leaders. 'The bear pit isn't the place for the weak. I won't be carrying you; you won't be carrying each other. This is war. It's about you versus them on the phones, and let me tell you, I'm backing you! Just remember we are a financial services company. Being target driven isn’t a choice, it's a lifestyle. We're all here to make sales, it's in our DNA, it's all there is. When I was on the floor working as a trader, I just wanted more, more, more. I want you to want more. I want you to want it so bad! So get in there, get me those numbers and enjoy your rewards! Don't think for one minute this is going to be easy, but just remember, when you feel like you can’t sell shit, it’s been a God-awful day and you're no way to your target, just remember when you're pointing the finger at the customer for not buying, pointing the finger at your managers for not helping you, pointing the finger at your buddy for doing more revenue than you, just remember there are three fingers right there pointing back at you! Go get 'em!'

Despite the optimism that surrounded training and the phased introduction to live calls, the initial hours and days were difficult for new recruits, many finding sales hard to generate whilst being left in doubt as to what their targets were.

'I want $£ 500$ revenue per day. Every call is a possible sale. If you don’t sell, I want to know why.' (Mark, team leader)

The intense focus on making sales had profound effects on employees, as witnessed, for example, in the development of forms of superstition surrounding the sale process and the importance attached to attaining the first sale, or 'getting one on the board'. 
'I made my first sale today, I felt so much better. I was worried about losing the sale, but I remember in training they said that it's almost impossible to lose a sale after the customer has agreed to buy.' (Leah, sales agent)

Whilst the pressure to attain targets was certainly evident, many agents spoke about more carnal and intrinsic motivations for achieving sales.

'It's like a drug this job. You get one and then you can’t get enough.' (Andrea, sales agent)

'It's best when you get one first thing in the morning. I need that to start the day right.' (Geoff, sales agent)

‘The “comedown” when you don't make a sale is awful. I hate it. I hate myself for failing.' (Nicki, sales agent)

As individual and team targets began to seem more difficult firstly to sustain and then even to attain, daily targets became broken down into hourly objectives. A well-established rule of thumb was that agents should be aiming to make one sale per hour, and that a 10 per cent conversion rate from calls to sales was considered the key to this. In training and embedded in practice, agents were encouraged to think about starting the day from zero to visualize how far they would have to go to achieve the day’s target. In such a performative context, simple greetings became an invitation to report on performance: 
Researcher 'Alright, Jim, how are you?'

Jim

'I’m already 70 per cent to goal - that's ace. I've still got four hours to go but I want to keep on, I want to smash it out the park!’

Yet, despite the visualization of future achievement, all agents faced the inescapable knowledge that future sales were, by their nature, unknowable and that there was an essential indeterminacy at the heart of the sales call. Agents quickly learnt, however, that irrespective of the specific customers that they spoke to and those customers' need or desire for the product, they were expected to make sales. Management and team leaders were keen to ensure that agents had no excuses for non-sales.

'Don't assume anything about the customer! It prevents you from selling and you can sell to everyone! Oldsters, youngsters, the unable and the infirm.' (Dean, Team Leader)

'Every call is a chance to sell, even if it's the wrong person - make sure you get to pitch! Sell, sell, sell, I want you to kill it.’ (Mark, Senior Operations Director)

Managers, marked out by their conspicuous consumption of energy drinks, were active figures around the call centre floor. They patrolled the catwalks throughout the day, theatrically prompting, goading and consoling, but always celebrating sales success. 'Revenue like a cricket score,’ screamed Josh, ‘9 for 588' - meaning nine sales generating $£ 588$ of revenue. Revenue figures began to dominate social interaction. “"How you doing?” (Sales agent mumbles response.) 'I’m not asking how you are; I’m not interested. I only want to know what you've sold.”' At hourly intervals managers began 'the count'. This involved 
the calculation of all team revenue, against target, to produce an hourly summary that was subsequently reported to the senior managers. Calculations were done whilst standing reviewing the whiteboard, newer managers with small pocket calculators, more senior managers with oversize ones, all jabbing furiously with index fingers.

Employees with previous sales experiences were quick to point out that the bonus regime at Praetorian was 'harsh'. Jim (a former call salesman), for example, commented: ‘Other places award bonuses on the basis of a percentage of all sales.' Moreover, those that had previous experience in financial services immediately recognized just how difficult it was to sustain the generation of revenue, at the required level, on a daily basis. As the difficulty of achieving targets became a reality to team members, their concerns began to grow. Stu, encouraged by initial sales success, bought a new car on finance shortly after he started work at Praetorian. Committed to long-term finance on the back of expected bonus earnings, he started to stay behind as the rest of the team left for breaks. Working through his lunch, stress, anxiety and fear became almost permanently etched on his face as the smile, wit and banter that I had so much enjoyed in training slowly disappeared.

With every call constructed as an 'opportunity to sell', agents were often put in a position of explaining their lack of sales. Placing emphasis on the agency of employees as sellers rather than on customers as buyers underlined the unquestioned logic of a 'sellers' market' that informed much of the behaviour I witnessed at Praetorian. Lack of sales was constructed as poor technique, motivation or both on behalf of employees, which further underscored the individual's responsibility for achieving sales at all costs.

Stu 'What's going on today? All the revenue is crap - no one is on it.' 
Dan 'I don’t know. You guys are on the phones - you tell me.'

Stu 'It's a really slow day today. No one is buying; it's hard to get the message over.'

Dan 'Oh, I must have missed that memo ... telling the world not to buy! Use what excuse you want to use, but I want to see sales. Now get back on the phones, get out of your chairs and start selling shit!’

(Re)producing the sales ritual

Despite the implied universality of the product, trainers and team leaders were keen to ensure that agents understood that effective sales techniques required subtlety, creativity and adjustments to approach, and hence deviation from the sales scripts. This was particularly the case as agents progressively became more familiar with the technical elements of the job and call handling became routine. Attention increasingly began to shift to the business of making sales, sometimes by any means, and this was accompanied by the development of a kind of 'folk knowledge' in relation to customers - a collective mythmaking that worked to close the gap between sales agents and customers and resolve the indeterminacy of the sale interaction. The perceived social status of customers, for example, was considered an important starting point. Maria told me how certain customers, who were dismissed by some agents as 'too poor to pay’, could sometimes ‘be manipulated into buying because of family concerns’. In this context, Dean suggested, 'Why wouldn’t you want to protect your family?' was an especially good question to ask of customers. By contrast, 'professionals' were viewed as able to see the technical benefits of the products, although often they would not buy on the principle 'it won’t happen to me'. [Comments collected from team review and debrief by team leader, trainers and sales director.] In this context, the sales advice was 'not to focus heavily on the features but rather to keep the tone light and build a connection through humour'. 
'Lower occupations get off on talking to someone professional - so when you talk about the product, make sure you make it very technical; give 'em the bullshit. If you are talking to a professional you'll not be able to bullshit them as much; they just want a laugh really.' (Mark, Sales Agent, transferred from another site)

The relentless nature of sales targets was inescapable and materialized at the end of each shift, as the agent with the highest revenue for the day was tasked with wiping the team's figures from the whiteboard in preparation for starting again at zero the following morning. This perfectly illustrated the irrelevance of previous sales performance and subordination of all other factors to the achievement of daily revenue targets. Incessant focus on actual sales meant that stories of 'near misses' became an important currency and source of social bonding for many employees. It provided both a form of peer support and commiseration in terms of how difficult it was to achieve the sale: '[I] could almost taste it, I was this close,' said Gill as she lamented another missed opportunity to sell.

The intense pressure to achieve revenue meant that targets measured in monthly terms started to feel far beyond the reach of many team members. As agents tried to make enough revenue to keep managers off their back, thoughts of bonuses and compliance slipped out of their minds:

Gill 'Yeah, the compliance stuff - I remember when I first started, I read all the red text, word for word. That didn’t last long. I started cutting corners, missing bits out, paraphrasing, you know, because at the end of the day, customers don't really want to hear that. They just want to get the product and get off the phone. It's not like we don't send them all the details in writing.' 
Sterling 'You've got to be really unlucky to get a compliance call. It's not like they can listen to all your calls, so basically I put a bit of the stuff (compulsory compliance text) into the conversations and leave some stuff out. I think it's a judgement call. Sometimes it's good for the punters to hear, gives reassurance, credibility even, to the company, like we're proper and you can trust us. Too much stuff though and it’s like, “Whoo, I'm not signing my life away.” It can be a real turn-off and you've lost the sale.'

Despite compliance clawbacks, as agents got progressively more experienced they inevitably started to drift away from compulsory scripting. This was facilitated by team leaders and managers, who recognized that effective sales required a departure from scripted interactions. In addition, some agents were openly sceptical about the extent and nature of Praetorian's compliance intentions.

Sam 'They (Praetorian) are not really interested in compliance. I mean, they say they are, but what else could they say? They know that if it's left to us down here (sales agents and team managers), we'll short-cut to get the sale. Listen to any call you like; there is no way it's 100 per cent compliant. Yet how often do you see someone get called up for it? As long as you're getting the revenue and making them look good, they don't care, and if it all goes bad they can point to the script and say, "Well, we told them what to say.”,

Further, as intimated by Stu, non-compliance to compulsory scripted text seemed to many agents a gamble, a risk worth taking. 
Stu 'I have to get that bonus; it's really important to me. I know I might lose some bonus via clawbacks, and that feels like a roulette wheel, but the odds are in my favour. If I don't get the bonus, though, that's different, I'll struggle to live, and that's Russian roulette - not a game I want to play.'

\section{Analysis}

By focusing on the initial training and day-to-day work of new sales agents, this article has foregrounded the importance and ritualistic nature of the sales interaction at Praetorian. The specific constituent ritual elements were: the clearly codified discrete steps of the sales process; the sequencing and management of the interaction by the sales agent; the collective rote learning in training; the putting into practice through forms of growing participation; the separation of buyer and seller into mutually exclusive categories; and, paradoxically, the assumed universalism of the product, itself a prerequisite for group membership. Ritual performances took place in a group context despite the physical separation of employees, customers and employers from one another whilst engaged in calls. The recording and celebrating of ritual performance are embodied individual and collective rites (Van Gennep, 1960) that play multiple social roles. Ritual is useful in making sense of the experience of employees at Praetorian and provides a foundation for understanding how mis-selling practices became embedded. It helps us to understand the nature of the training undertaken, the way employees were taught to think about and manage customer interactions, and the scope for creativity and diversions from scripting it provided. Ritual is thus an apt characterization of the required form that work performances took, whilst ritualistic is a useful description of the content of customer interactions. 
When understood as a ritual, the sales interaction, as the most basic premise of the organization, was revealed as a normalizing code that constituted a framework for employee understanding, meaning, purpose and inculcation of values (Stephenson, 2015: 41). The sales ritual materialized the belonging of employees through the demand for repetitive performance, but also placed individuals within a collective context. This was achieved through repeated references to the number of trainees who had been through the initial induction programme, for example. The practice of ritual allowed, and even required, deviation and creativity in enactment as a sign of individual maturity and competence. Thus sales rituals were never entirely prescribed nor employees enveloped. Therefore, whilst specific individual linguistic utterances were important (and the subject of regulatory focus), the nuance and dynamic nature of sales interactions means that both form and content are analytically significant. Thus sales calls, which took the form of elongated greetings at Praetorian, demanded, 'as with all social relationships[,] reciprocity ... an expectation in greeting is that it will elicit social recognition in return' (Firth, 1972: 2). Attention to the form that sales interactions took thus highlights the structuring properties of ritual in patterning socially acceptable engagement for both employees and customers and the establishing of terms of engagement. The importance of ritual also alerts us to its ongoing role in socialization. Thus, following Michel (2014: 1107), we might conceive that the role played by everyday aspects of organizational practice (such as specific lines of scripted text and otherwise apparently innocuous greetings) in shaping employees and mapping the landscape of interaction is far more comprehensive than previously thought.

Ritual tells us much about how employees at Praetorian come to think and behave in certain ways but raises questions of how and why these patterns of interaction constitute mis-selling and the specific relationship between these and other forms of mis-selling. In foregrounding 
the experience of front-line sales staff, we see how ritual produced mis-selling as constituted in the deliberate and negligent sale of financial services. The ritual provided interactive space for employees to draw on sophisticated sales repertoires in attempting to influence and persuade customers of their need for Praetorian products and services, whilst at the same time, convincing customers its intent was benign. Here the sales interaction is negligent in the sense that both the organization and employee fail in their duty of care to treat customers fairly by selling products that were, in a practical sense, unnecessary. Customer objections existed to be overcome and the actual usefulness of the product and the customer's desire for it thus essentially rendered irrelevant.

This genus of mis-selling exhibits both continuities and differences with other forms. The mis-selling of pensions for example, primarily involved negligence in terms of the discharge of poor advice from advisors in relation to moving from occupational and defined benefit schemes to private pension provision with variable returns. Individual advisors earned commission whilst the insurance industry charged high administrative and management fees. This is similar to the case of Praetorian with advisors incentivised to persuade customers without sufficient scrutiny or consideration of the actual likely benefit. Unlike pensions misselling however the impetus for the purchase of Praetorian's products was generally to have short to medium term protection against criminal activity. The risk of which, employees grew adept at exaggerating. The mis-selling of endowment policies or secondary insurance linked to primary interest-only mortgages, offered borrowers a way to generate sufficient capital on maturity to repay the capital component of the primary borrowing. The negligent sale of these policies related to the complexity of the endowment structure and the over-optimistic appraisal of endowment performance. With many customers being left with significant shortfalls, here again we see the influence of commission-based incentives for the individual 
advisor coupled with a systemic failure to ensure that customers were able to accurately grasp and assess product related risk. In the case of Praetorian, customers' feelings of being 'at risk’ were distorted whilst consumers of endowment products often lacked an insight to the risks associated with products link to investment fund performance. It is however the misselling of PPI, or secondary products to cover borrowing payments in the event of accident, sickness or job loss, that is most closely related to mis-selling of Praetorian. Here policies were often excessively priced adding significantly to the original costs of borrowing whilst being sold to many whom were unable claim due to policy exclusions. Whilst sales agents at Praetorian often tried to convince customers of the value of the product, the complexity of the policy and redundancy inherent within it meant that in many cases customers were paying for protection that they already possessed rendering the policy literally worthless. Yet in stark contrast to all the major forms of mis-selling, Praetrorian is unique in its deployment of the masquerade central to its business model; ironically and inauthenticly pretending to be customer's banks in order to sell identity protection.

Praetorian sought to routinize compliance through scripting but, in line with research on the implementation of organizational regulation, effectively devolved this to managers and individual sales agents. The reasons for this, whilst beyond the scope of this article, are important but remain unclear. Whilst not without precedent, regulatory and compliance information is, for many firms, pre-recorded to ensure consistency, and this could have been an approach adopted by Praetorian if it had wished. The case study shows clearly that although compliance to sales guidelines was a feature of training and was actively enforced, management's central concern remained the generation of revenue. Compare for example the codified nature of scripted compliance with the animated insistence on sales. Agents did, initially at least, adopt strategies to balance sales with compliance issues. Sales agents knew 
the importance of compliance, but often spoke about compliance in the past tense whilst foregrounding the immediacy of revenue generation. Given the target-based environment and the energy that team leaders put into encouraging sales, this is hardly surprising, and there is inevitability about the way in which compliance issues gradually faded from view. By putting the onus for compliance on individuals, Praetorian appeared to benefit by avoiding overly tight scripting of the sales interaction, which was seen as an asset in the generation of authentic customer interactions. This has significance for thinking about the design of regulatory environments and problematizes those frameworks that are built upon assumptions that management are willing and able to enforce ethical practice.

For sales agents, to whom compliance was delegated, compliance was constructed in relation to specific ideas of how products should be sold, or, more specifically, the exact lines of dialogue, including terms and conditions, costs, coverage of policies and cancellation rights which had to be articulated during each transaction. Given the time-constrained nature of the customer interaction, it is perhaps not surprising that agents progressively populated this space with sales techniques rather than compliance information. In doing this, agents drew upon linguistic resources that were provided in training and learnt in a ritualistic fashion. The shifting of the regulatory burden to the lowest-possible organizational stratum effectively allowed individuals to determine their own level of compliance through self-regulation. Despite the presence of direct monitoring by team leaders, managers and an internal regulatory department, penalties for poor compliance, and external regulation by the FSA, I show how compliance was overlooked in pursuit of sales and how the sales ritual at Praetorian provided space for individuals to engage in mis-selling. 
Existing literature provides useful insights, at the individual level, into why agents may engage in unethical behaviour. Yet comprehending the widespread scale and embedded nature of mis-selling and other forms of financial misconduct, both at Praetorian and in the UK's financial services more generally, demands analytical categories that transcend yet comprehend individual behaviour. Work that focuses on individual decisions to engage in unethical behaviour often over-emphasizes the scope of choice that patterns of requisite organizational engagement afford employees. Explanations and accounts of financial misconduct (together with the GFC more generally), both popular and scholarly, feature notions of culture heavily. Cultural explanation provides a way of understanding mis-selling that renders certain actions and behaviours acceptable in a given context and is therefore essentially permissive. However, cultural explanations risk reductive over-generalization and consequent essentializing of mis-selling whilst failing to note the nuance of agents’ experience and potential to do otherwise. Moreover, recourse to generalized cultural explanations in accounting for behaviour without detailed empirical study of behaviours in context risks becoming a clichéd form of analysis that strips the analytical category of culture of all explanatory power. A notable feature of the case study, for example, is the total lack of recourse to 'culture' made by Praetorian during initial training. New employees were not presented and asked to buy into a vision of Praetorian's culture; rather, they were invited to buy in to the product as a condition of group membership and then asked to sell this product to customers.

Whilst this analysis could be read as questioning the value of cultural explanations in accounting for mis-selling and financial misconduct more generally, the intention is not to claim that culture is unimportant. Rather, this analysis suggests that, at least in organizational contexts, we might be more cautious in the way in which we use culture as a tool for analysis. 
Membership of any organization constrains and limits the possible available choices for action and is therefore a cultural form, 'a product of a particular sociohistorical context and embodying [of] particular value commitments' (Smircich, 1983: 355). Analysis of cultural forms requires an understanding of what agents bring into being in terms of specific individual histories, knowledge and experience as well as bodily endowment, and what this means for the way in which organizational contexts and demands are interpreted, understood and reproduced. The former used-car salesman, for example, always understood the bonus structure at Praetorian to be problematic. Yet, frequently, analysis which foregrounds the role of culture treats those subject to it as if they are blank slates, without history or perspective. Consequently, rather than resorting to cultural explanation as a starting point, the analysis presented here encourages future empirical work to look towards those aspects of everyday organizational experience and practice that normally 'we collapse into the label of organizational culture' (Pettigrew, 1979: 572). That is to say, refocusing our analysis on those things that are more often dismissed as the product of culture might actually provide greater insight into the production of culture. This helps us to understand why new employees who have little or no previous experience of and thus exposure to organizational culture are so quickly able to engage in mis-selling. Mis-selling is thus not a cultural effect, but is produced through performance of ritual, and thus partially at least works to subsume psychology and structure, and performs rather than emerges from culture.

\section{Conclusion}

In seeking to explore the organizational dynamics of mis-selling, and how this emerges in a regulated context, this article draws attention to the role of the sales ritual in patterning the thinking and behaviour of sales agents. The case study also draws attention to the way in which ritual produces culture. This insight has wider significance with regard to the 
analytical value of the concept of culture in understanding the mis-selling phenomenon. Invoking sociological notions of culture that assume deeply sedimented forms of human activity and ‘tradition’ (Buono et al., 1985: 482) can only be of limited relevance in fastpaced environments such as the call centre sales floor and may only be partially relevant to organizational contexts more generally. To what extent, for example, can a newly opened call centre be said to have a culture in any distinct sense? Can that culture be so robust as to substantively influence the behaviour of employees after only two weeks of exposure? Yet without recourse to notions of culture, how might we explain the systematic collective behaviour of individual autonomous sales agents? The contribution of this article is to shift attention away from individual explanations of misbehaviour whilst also raising questions about the analytical use of culture, in its permissive form, and its explanatory potential in contemporary organizational contexts, which often seem to be marked by change, disruption and reconfiguration. By focusing upon the essential rituals of organizations, frequently mistaken as products of culture and hidden in plain sight, the response offered here moves attention to an understanding of the mechanisms that actually produce culture.

Participative fieldwork, and the attention this gives to the routines and rituals of everyday life in the call centre, is important in terms of understanding the role of mis-selling and how this is embedded within organizational practices. This contribution therefore serves as a partial corrective to the insistent focus upon professional elites, especially within the financial services industry, in relation to both GFC and misconduct more generally. An exclusive focus on hierarchy tends to reify the role of leadership and universalize particular sets of values that are associated with it. Moreover, as Mathiesen (1997) suggests, in the case of wrongdoing, existing social arrangements are effectively legitimized with such a focus, albeit at the cost of successive token sacrifices. In doing so, the illusion of control is maintained, which provides 
a means for the many to see the few (Levi, 2006: 1050), with 'business as usual' allowed to continue. In part, the contribution made here may help to overcome the demonization of employees in the financial services industry, yet it also helps us to understand that unethical behaviour is endemic and systematic, and is far from abnormal or restricted to a select few firms or key individuals. Understanding ritual everyday organizational practices highlights the grounds on which participation is expected from employees and demonstrates the limits and constraints that govern the ways in which relationships with customers can exist. This transcends individualistic psychological approaches to mis-selling and offers a way of thinking about how individual action is brought into being in collective contexts, thus providing a starting point for thinking about organizational interventions.

In a wider context, the analysis presented here has specific implications for the growing trend towards culture as a descriptive panacea (as opposed to an analytical device), which identifies culture as the universal explanation for misbehaviour within organizations. In the UK, for example, culture has become a key feature of the public understanding of wrongdoing in a number of organizational and institutional contexts. ${ }^{3}$ In many of these cases, culture as a specific form within a single organization, or as a more general form and set of practices and expectations within an industry, is accorded a significant role in allowing or facilitating the most serious and egregious conduct. The case made here suggests that recourse to this idea of culture - without a detailed empirical investigation of the mundane routines that constitute organizational life and the practices that are afforded and limited within it - is an explanation that is empty of meaning. The challenge this poses for organizational scholars, therefore, is to seek a more finely grained analysis of our notions of culture as they pertain to organizational contexts and to re-tool our collective research methods so that we might explore culture, and the everyday practices that produce it, more fully, more critically, more ethnographically. 


\section{Acknowledgements}

The author would like to thank Paul Edwards and three anonymous reviewers for their helpful and insightful comments on this paper. In addition the initial ideas and early drafts of the paper were discussed extensively with Caroline Clarke, Lindsay Hamilton, Geoff Heath, Aleksandra Jordanosk, David Knights, Anita Mangan, Cinzia Priola, Malik Salameh, Frank Worthington and the participants of the Organization Studies Network, Ethnography Symposium, and an Open University Business School seminar 2015.

\section{Funding}

This research received no specific grant from any funding agency in the public, commercial, or not-for-profit sectors.

\section{Notes}

${ }^{1}$ In the UK, the Financial Services Authority (FSA) provided regulation for the financial services industry (initially banking supervision and investment services, but growing to include mortgage and general insurance) from 1997 to 2013. The FSA was succeeded by the Financial Conduct Authority (FCA), which now has responsibility for integrity and stability of markets and ensuring a fair deal for customers. The Prudential Regulation Authority (PRA), a part of the Bank of England, has responsibility for maintaining safety and soundness of individual firms, whilst both regulators have a mandate to promote competition within the various retail financial markets.

${ }^{2}$ Tom Hayes is a former UBS and Citigroup trader who, in August 2015, was sentence to 14 years in prison financial misconduct. Although this was reduced to 11 years on appeal, it 
remains the most severe sentence imposed on an individual for financial crime un the UK. It was alleged by the prosecution that Hayes led a conspiracy to artificially manipulate the London Interbank Offered Rate (LIBOR) benchmark, in order to benefit his own trades. Throughout the trial and subsequent appeal, Hayes claimed such manipulation of the rate was standard practice within the industry and conducted in full knowledge of senior bank management.

${ }^{3}$ See for example the Parliamentary Commission on Banking Standards report Changing Banking for Good (2013), which locates culture as central to understanding successive financial scandals, but also key to the sector's reform: 'Banking culture has all too often been characterised by an absence of any sense of duty to the customer and a similar absence of any sense of collective responsibility to uphold the reputation of the industry' (Para 135). See also the Independent Panel on Hillsborough (2012), which notes that the 'culture of the police was influential' in the way in which football matches were policed and that police defendants were guilty of negligence in relation to the duty of care that they had to the deceased (Hillsborough, 2012: 56). See also the Leveson Inquiry (2012), established specifically to review the culture, practice and ethics in the British press, which found a culture of 'recklessness in prioritising sensational stories, almost irrespective of the harm that the stories may cause and the rights of those who would be affected (perhaps in a way that can never be remedied), all the while heedless of the public interest'. See also the case of the report into poor care and high mortality at Stafford Hospital. The official report found that MidStaffordshire NHS Foundation Trust 'failed to tackle an insidious negative culture involving a tolerance of poor standards and a disengagement from managerial and leadership responsibilities' (Francis, 2013). See also Alexis Jay’s report into child exploitation in Rotherham, which stated: 'The prevailing culture at the most senior level of the Council, until 
2009, as described by several people, was bullying and “macho”, and not an appropriate climate in which to discuss the rape and sexual exploitation of young people.' See also the report on lessons learnt from NHS investigations into matters relating to Jimmy Savile (2015), in which Kate Lampard and Ed Marsden found the NHS at the time to 'lack a culture where whistle-blowing can take place'.

\section{Funding}

This research received no specific grant from any funding agency in the public, commercial, or not-for-profit sectors.

\section{Notes}

${ }^{1}$ In the UK, the Financial Services Authority (FSA) provided regulation for the financial services industry (initially banking supervision and investment services, but growing to include mortgage and general insurance) from 1997 to 2013. The FSA was succeeded by the Financial Conduct Authority (FCA), which now has responsibility for integrity and stability of markets and ensuring a fair deal for customers. The Prudential Regulation Authority (PRA), a part of the Bank of England, has responsibility for maintaining safety and soundness of individual firms, whilst both regulators have a mandate to promote competition within the various retail financial markets.

${ }^{2}$ Tom Hayes is a former UBS and Citigroup trader who, in August 2015, was sentence to 14 years in prison financial misconduct. Although this was reduced to 11 years on appeal, it remains the most severe sentence imposed on an individual for financial crime un the UK. It was alleged by the prosecution that Hayes led a conspiracy to artificially manipulate the London Interbank Offered Rate (LIBOR) benchmark, in order to benefit his own trades. Throughout the trial and subsequent appeal, Hayes claimed such manipulation of the rate was 
standard practice within the industry and conducted in full knowledge of senior bank management.

${ }^{3}$ See for example the Parliamentary Commission on Banking Standards report Changing Banking for Good (2013), which locates culture as central to understanding successive financial scandals, but also key to the sector's reform: 'Banking culture has all too often been characterised by an absence of any sense of duty to the customer and a similar absence of any sense of collective responsibility to uphold the reputation of the industry’ (Para 135). See also the Independent Panel on Hillsborough (2012), which notes that the 'culture of the police was influential' in the way in which football matches were policed and that police defendants were guilty of negligence in relation to the duty of care that they had to the deceased (Hillsborough, 2012: 56). See also the Leveson Inquiry (2012), established specifically to review the culture, practice and ethics in the British press, which found a culture of 'recklessness in prioritising sensational stories, almost irrespective of the harm that the stories may cause and the rights of those who would be affected (perhaps in a way that can never be remedied), all the while heedless of the public interest'. See also the case of the report into poor care and high mortality at Stafford Hospital. The official report found that MidStaffordshire NHS Foundation Trust 'failed to tackle an insidious negative culture involving a tolerance of poor standards and a disengagement from managerial and leadership responsibilities’ (Francis, 2013). See also Alexis Jay’s report into child exploitation in Rotherham, which stated: 'The prevailing culture at the most senior level of the Council, until 2009, as described by several people, was bullying and "macho”, and not an appropriate climate in which to discuss the rape and sexual exploitation of young people.' See also the report on lessons learnt from NHS investigations into matters relating to Jimmy Savile 
(2015), in which Kate Lampard and Ed Marsden found the NHS at the time to 'lack a culture where whistle-blowing can take place'. 


\section{References}

Aldridge, A (1997) Engaging with promotional culture: organised consumerism and the personal financial services industry. Sociology 31(3): 389-408.

Ali, S and Kelly, M (2012) Ethics and social research. In: Seale, C (ed.), Researching society and culture, London, Sage, 59-73.

Allon, F (2009) The futility of extrapolation: reflections on crisis, continuity and culture in the 'Great Recession'. Ephemera: Theory and Politics in Organization, 9(4): 369-79.

Alloway, T, Braithwaite, T and Schafer, D (2012) Goldman accused of 'toxic' culture by departing banker. Financial Times, 15 March 2012.

http://search.proquest.com/docview/928124204?accountid=11814 (accessed 24 February 2016).

Ashkanasy, NM, Windsor, CA and Treviño, LK (2006) Bad apples in bad barrels revisited: Cognitive moral development, just world beliefs, rewards, and ethical decision-making. Business Ethics Quarterly, 449-73.

Ashton, JK and Hudson, RS (2012) The mis-selling of payments protection insurance in mortgage and unsecured lending markets. In: Juan Fernández de Guevara Radoselovics, José Pastor Monsálvez (eds) Modern Bank Behaviour. London: Palgrave. 8-33.

Benston, GJ (1999) Regulating financial markets: a critique and some proposals. American Enterprise Institute. Washington: AEI Press. 
Black, J and Nobles, R (1998) Personal pensions misselling: The causes and lessons of regulatory failure. The Modern Law Review, 61(6): 789-820.

Blau, PM (1960) A theory of social integration. American Journal of Sociology, 545-56. Bloor, M (1997) Addressing Social Problems through Qualitative Research. In Silverman (ed.) Qualitative Research: Theory, method and practice. London: Sage, 221-38.

Braithwaite, V and Braithwaite, J (2006) Democratic sentiment and cyclical markets in vice. British Journal of Criminology, 46(6): 1110-27.

Brannan, MJ, Pearson, G and Worthington, F (2007) Ethnographies of Work and the Work of Ethnography, Ethnography, 8(4): 395-402.

Bulmer, M (ed.) (1982) Social Research Ethics. London: Macmillan.

Buono, AF, Bowditch, JL and Lewis, JW (1985) When cultures collide: The anatomy of a merger. Human Relations 38(5): 477-500.

Burton, D, Knights, D, Leyshon, A, Alferoff, C and Signoretta, P (2004) Making a market: the UK retail financial services industry and the rise of the complex sub-prime credit market. Competition and Change 8(1): 3-25.

Calvey, D (2008) The Art and Politics of Covert Research: Doing 'Situated Ethics' in the Field. Sociology 42(5): 905-18. 
Chreim, S (2006) Managerial frames and institutional discourses of change: Employee appropriation and resistance. Organization Studies 27(9): 1261-87.

Cohan, WD (2010) House of cards: A tale of hubris and wretched excess on Wall Street. Anchor.

Cooper, M (2008) The inequality of security: Winners and losers in the risk society. Human Relations 61(9): 1229-58.

De Vita, G. and Case, P., (2016) 'The smell of the place': Managerialist culture in contemporary UK business schools. Culture and Organization, 22(4): 1-17.

Dietz, J, Pugh, SD and Wiley, JW (2004) Service climate effects on customer attitudes: An examination of boundary conditions. Academy of Management Journal 47(1): 81-92.

Ericson, RV and Doyle, A (2006) The Institutionalization of Deceptive Sales in Life Insurance: Five Sources of Moral Risk. British Journal of Criminology 46(6): 993-1010.

Faden, RR, Beauchamp, TL and King, NM (1986) A history and theory of informed consent. Clarendon Press.

Felps, W, Mitchell, TR and Byington, E (2006) How, when, and why bad apples spoil the barrel: Negative group members and dysfunctional groups. Research in Organizational Behaviour 27, 175-222. 
Ferran, E (2012) Regulatory Lessons from the Payment Protection Insurance Mis-selling Scandal in the UK. European Business Organization Law Review 13(2), 247-70.

Financial Conduct Authority (2014) Redress for payment protection insurance (PPI) missales: Update on progress and looking ahead, London [ONLINE] Available at: http://www.fca.org.uk/static/documents/thematic-reviews/tr14-14.pdf (accessed 29 May 2015).

Financial Services Authority (2013) Interest Rate Hedging Products, Financial Service Authority, London.

Financial Services Authority (2013b) Final Guidance. Risk to Customers from Financial Incentives Interest, Financial Service Authority, London.

Fine, GA (1993) Ten Lies of Ethnography: Moral Dilemmas of Field Research. Journal of Contemporary Ethnography 22(3): 267-94.

Firth, R (1972) Verbal and bodily rituals of greeting and parting. In: La Fontaine, JS (1972) The interpretation of ritual: essays in honour of AI Richards. London: Tavistock Publications.

Francis, R (2013) Report of the Mid Staffordshire NHS Foundation Trust Public Inquiry. Executive Summary. London: The Stationery Office. 
Georgosouli, A (2011) The FSA's 'Treating Customers Fairly’ (TCF) initiative: What is so good about it and why it may not work. Journal of Law and Society 38(3): 405-27.

Ghoshal, S. and Bartlett, C.A., (1994) Linking organizational context and managerial action: The dimensions of quality of management. Strategic Management Journal 15(S2): 91-112.

Gilad, S (2011) Institutionalizing fairness in financial markets: Mission impossible? Regulation \& Governance 5(3): 309-32.

Gino, F, Ayal, S and Ariely, D (2009) Contagion and differentiation in unethical behaviour: the effect of one bad apple on the barrel. Psychological Science 20(3): 393-98.

Goodhart, C, Hartmann, P, Llewellyn, DT, Rojas-Suarez, L and Weisbrod, S (2013) Financial regulation: Why, how and where now? Routledge.

Gunz, H and Gunz, S (2007) Hired professional to hired gun: An identity theory approach to understanding the ethical behaviour of professionals in non-professional organizations. Human Relations 60(6): 851-87.

Haggerty, KD (2004) Ethics creep: Governing social science research in the name of ethics. Qualitative Sociology 27(4): 391-414.

Hargie, O, Stapleton, K and Tourish, D (2010) Interpretations of CEO public apologies for the banking crisis: attributions of blame and avoidance of responsibility. Organization 17(6): 721-42. 
Harris, L (2002) The learning organisation - myth or reality? Examples from the UK retail banking industry. The Learning Organization 9(2): 78-88.

Highmore, B., 2002. Everyday life and cultural theory: An introduction. Routledge.

Hillsborough (2012) The Report of the Hillsborough Independent Panel. London, HMSO. Homan, R (1991) The ethics of social research, London: Macmillan.

Jaakkola, E (2011) Unraveling the practices of “productization” in professional service firms. Scandinavian Journal of Management 27(2): 221-30.

Jay, A (2014) Independent Inquiry into Child Exploitation in Rotherham 1997-2013. Rotherham Metropolitan Borough Council.

Johnson, S and Kwak, J (2011) 13 bankers: The Wall Street takeover and the next financial meltdown. Vintage Books USA.

Kalekin-Fishman, D (2013) Sociology of everyday life. Current Sociology 61(5-6): 714-32.

Karpoff, JM, Lee, DS and Martin, GS (2008) The cost to firms of cooking the books. Journal of Financial and Quantitative Analysis 43(03): 581-611.

Karstedt, S and Farrall, S (2006) The moral economy of everyday crime: Markets, consumers and citizens. British Journal of Criminology 46(6): 1011-36. 
Kerfoot, D and Knights, D (1993). Management, masculinity and manipulation: from paternalism to corporate strategy in financial services in Britain. Journal of Management Studies 30(4): 659-77.

Kerr, R and Robinson, S (2012) From symbolic violence to economic violence: The globalizing of the Scottish banking elite. Organization Studies 33(2): 247-66.

Kish-Gephart, JJ, Harrison, DA and Treviño, LK (2010) Bad apples, bad cases, and bad barrels: meta-analytic evidence about sources of unethical decisions at work. Journal of Applied Psychology 95(1): 1.

Knights, D and McCabe, D (1997) 'How would you measure something like that?': Quality in a retail bank. Journal of Management Studies 34(3): 371-88.

Knights, D and McCabe, D (1998) 'What happens when the phone goes wild?': staff, stress and spaces for escape in a BPR telephone banking work regime. Journal of Management Studies 35(2): 163-94.

Knights, D and McCabe, D (2015) 'Masters of the Universe': Demystifying Leadership in the Context of the 2008 Global Financial Crisis. British Journal of Management 26(2): 197-210.

Knights, D and Willmott, HC (1987) Organizational culture as management strategy: A critique and illustration from the financial services industry. International Studies of Management \& Organization 17(3): 40-63. 
Knights, D and Willmott, H (1992) Conceptualizing Leadership Processes: A Study of Senior Managers in a Financial Services Company. Journal of Management Studies 29(6): 761-82.

La Fontaine, JS (1972) The interpretation of ritual: essays in honour of AI Richards. London: Tavistock Publication.

Langley, P (2008) Sub-prime mortgage lending: a cultural economy. Economy and Society 37(4): 469-94.

Lave, J and Wenger, E (1991) Situated learning: Legitimate peripheral participation. Cambridge University Press.

Leveson (2012) Enquiry into the culture, practice and ethics of the press. Executive summary and recommendations. London: The Stationery Office.

Levi, M (2006) The media construction of financial white-collar crimes. British Journal of Criminology 46(6): 1037-57.

Llewellyn, D (1999) The economic rationale for financial regulation. London: Financial Services Authority.

Lupton, D (1999) Risk and sociocultural theory. In: Lupton, D (ed.) Risk and sociocultural theory - New directions and perspectives. Cambridge University Press, Cambridge. 
Luyendijk, J (2015) Swimming with the sharks: my journey into the world of the bankers. London: Guardian Books/Faber \& Faber.

MacNeil, I (1999) The Future for Financial Regulation: The Financial Services and Markets Bill. The Modern Law Review 62(5): 725-43.

Mathiesen, T (1997) The Viewer Society: Michel Foucault’s ‘Panopticon’ Revisited, Theoretical Criminology 1(2): 215-34.

McBarnet, D (2006) After Enron will 'Whiter than white collar crime’ still wash? British Journal of Criminology 46(6): 1091-109.

McCabe, D (2009) Enterprise contested: Betwixt and between the discourses of career and enterprise in a UK bank. Human Relations 62(10): 1551-79.

Michel, A (2014) The mutual constitution of persons and organizations: An ontological perspective on organizational change. Organization Science 25(4): 1082-110.

Nayak, A and Beckett, A (2008) Infantilized adults or confident consumers? Enterprise discourse in the UK retail banking industry. Organization 15(3): 407-25.

Nelken, D (2012) White-collar and corporate crime. In: Maguire et al. (eds.) The Oxford Handbook of Criminology, 4th edition. Oxford: Oxford University Press. 
Parliamentary Commission on Banking Standards (2013) Changing Banking for Good. London: The Stationery Office.

Pettigrew, AM (1979) On studying organizational cultures. Administrative Science Quarterly 24(4): 570-81.

Rappaport, RA (1992) Ritual in Folklore, Cultural Performances and Popular Entertainments. Ed. by Richard Bauman. New York.

Rosen, M (2000) Turning words, spinning worlds: Chapters in organizational ethnography (Vol. 2). Psychology Press.

Rynes, S.L., (2007) Editor's Foreword: Carrying Sumantra Ghoshal's Torch: Creating More Positive, Relevant, and Ecologically Valid Research. The Academy of Management Journal, 50(4): 745-747.

Smircich, L (1983) Concepts of culture and organizational analysis. Administrative Science Quarterly 28(3): 339-58.

Spicker, P (2011) Ethical covert research. Sociology 45(1): 118-33.

Stephenson, B (2015) Ritual: A Very Short Introduction. Oxford University Press. Sztompka, P (2008) The focus on everyday life: A new turn in sociology. European Review 16(01): 23-37. 
Tempest, S, McKinlay, A and Starkey, K (2004) Careering alone: Careers and social capital in the financial services and television industries. Human Relations 57(12): 1523-45.

Tett, G (2009) Fool's Gold: How Unrestrained Greed Corrupted a Dream, Shattered Global Markets, and Unleashed a Catastrophe. London, Little Brown.

Thaler, RH and Sunstein, CR (2009) Nudge: Improving Decisions About Health, Wealth and Happiness. Penguin UK.

Treviño, LK and Youngblood, SA (1990) Bad apples in bad barrels: A causal analysis of ethical decision-making behaviour. Journal of Applied Psychology 75(4): 378.

Van Gennep, A (1960) The Rites of Passage. University of Chicago Press.

Ward, V (2010) The devil's casino: Friendship, betrayal, and the high stakes games played inside Lehman Brothers. John Wiley \& Sons.

Watson, R (2008) A review of the risks, costs and benefits of defined contribution and defined benefit pension schemes. Journal of Financial Regulation and Compliance 16(3): 230-8.

Watson, TJ (2003) Ethical choice in managerial work: The scope for moral choices in an ethically irrational world. Human Relations 56(2): 167-85. 
Watson, TJ (2011) Ethnography, reality, and truth: the vital need for studies of 'how things work' in organizations and management. Journal of Management Studies 48(1): 202-17.

Weeks, J (2004) Unpopular culture: The ritual of complaint in a British bank. University of Chicago Press.

Whittle, A and Mueller, F (2012). Bankers in the dock: Moral storytelling in action. Human Relations 65(1): 111-39. 
Figure 1: Field document 1 'praetorian facts'

\author{
IPA STATS AND TIPS \\ $5 / 3$ \\ It can cost a victim of identity theft up to $£ 8,000$ and take over 200 hours of their time to \\ restore their reputation in extreme cases. - CIFAS 2008 \\ $92 \%$ of identity frauds are not reported to the police - Experian (April 2007) \\ 16,500 fraudulent applications for passports were received by the Identity Passport Service \\ (IPS) in the 12 months t September 2006. - CIFAS \\ Over 10,000 fraudulent passport applications each year - UK Passport Service 2007
}

$41 / 2$

There are 80 million active $\mathrm{NI}$ numbers in the UK which has a population of 60 million. CIFAS 2006

Over 185,000 victims of fraud during 2007, around an $8 \%$ increase on 2006 - CIFAS Jan 2008

Nearly 1 in 10 Britons believe they have been the victim of identity theft - YouGov 2006

UK Online banking fraud leapt $44 \%$ in 2006 following a rise in the number of phishing attacks - APACS study 2007

Instances of a fraudster getting access to their victims existing account rose by $34 \%$ during 2007 - CIFAS Jan 2008

The top three false or stolen documents used by fraudsters to attempt identity fraud in 2007 were: non-UK passports, followed by utility bills and then UK passports. -CIFAS Jan 2008

Card-not-present fraud (skimming, stolen data etc.) is now the largest type of card fraud and reached £290million in 2007 an increase of $37 \%$ over the previous year - APACS Mar 2008.

Every year 1 in 15 Britons fall victim to scams involving deceptive unsolicited mailings, phone calls or emails - OFT 2006

$55 \%$ of victims of id theft found out through accessing their credit report - Experian Victims of Fraud dossier 2007

Facility takeover (also known as account takeover) occurs when the fraudster impersonates a victim in order to 'take over' and control one or more of the victim's existing accounts. In 2007 , ClFAS Members saw an increase in this type of fraud of over $34 \%$. CIFAS

The number of cases identified, 57,302 , is worryingly high, with the number of victims increasing by nearly $2 \%$ to 52,167 . - CIFAS

Your post can be fraudulently redirected to another address so fraudsters can get hold of important documents.

On average it takes 467 days to discover that you are a victim of identity fraud, according to Experian. With our policy we will alert you if there are any changes to your credit report, meaning the problem can be resolved before it gets our of hand

It can take up to 15 months to discover you have been the victim of Identity Theft. - Office of the Data Protection Supervisor (April 2007) 
[Query to Author: Please insert author biog with email address here - many thanks]

Matthew J. Brannan is a senior lecturer in Management at Keele Management School, Keele University. His research explores the growth of the Service Sector and the implications this has for contemporary experiences of work. He has written about the use of role-play in Call Centre recruitment and selection processes, the engagement of worker's sexuality in customer service environments, the career path of female junior managers and Employee Branding. He is editor of the Journal of Organizational Ethnography and a founder member of the Annual Liverpool, Keele Ethnography Symposium.

\section{Corresponding author:}

Matthew J Brannan

Keele Management School

Darwin Building

Keele University

Staffordshire

ST5 5BG

UK

m.brannan@keele.ac.uk 